\section{Comment on 'Vasectomy: replacing the preoperative outpatient appointment with a DVD'}

The article by Amanda Davies and Charlotte Fleming ${ }^{1}$ describes what we have been practising for many years.

We have run a direct access service dealing with over 4000 patients. The service has been well received with $96 \%$ of a sample grading it as good or excellent. ${ }^{2}$

We do not see the need for a preoperative consultation and agree with the authors that this does not add any quality to the service or the patient journey. Advice and information provided by the referring general practitioner is considered adequate.

In our service, when the patient attends on the day a short discussion takes place with the patient and with the partner if present. This discussion touches upon complications including pain, natural reversal rate of the procedure, postoperative seminal fluid analysis and the need for continuing contraception after surgery. Most, if not all, patients are adequately informed when they attend. This process aids informed consent.

However, the need for a preoperative consultation is advised in the following circumstances: (1) in patients who have had inguino-scrotal surgery (e.g. for undescended testis, hernia repair, excision of hydrocele, etc.) and (2) a repeat procedure following failure of vasectomy or vasectomy after reversal. In these situations it is useful to know if the vas is palpable, not surrounded by dense fibrous tissue and hence exteriorised relatively easily under local anaesthesia.

Austin Chukwu, MRCGP, FRCS

General Practitioner, The Hamilton Practice, Harlow, UK; austinchukwu@nhs.net

Ken Menon, FFSRH, FRCS

General Practitioner, The Hamilton Practice, Harlow, UK; kenmenon@aol.com

Competing interests None.

J Fam Plann Reprod Health Care 2014:40:73. doi:10.1136/jprhc-2013-100815

\section{REFERENCES}

1 Davies A, Fleming C. Vasectomy: replacing the preoperative outpatient appointment with a DVD. J Fam Plann Reprod Health Care 2014;40:61-62. [Published online 27

September 2013]
2 Menon NK. Patient satisfaction with a direct access vasectomy service. Br J Fam Plann 1998;24:105-106. 